\title{
Creatine supplementation and exercise as possible therapeutic treatments in Parkinson's Disease: A review
}

\author{
Graham SM${ }^{1}$, Baird $\mathbf{M}^{1}$, Boyd $\mathbf{G W}^{2}$ \\ ${ }^{1}$ School of Life, Sport \& Social Sciences, Edinburgh Napier University, United Kingdom \\ ${ }^{2}$ School of Science, University of West of Scotland, United Kingdom
}

\begin{abstract}
Parkinson's disease (PD) is the second most common progressive neurodegenerative condition after Alzheimer's Disease. It is characterized by a progressive loss of dopaminergic neurons in the substantia nigra region of the brain. Symptoms and signs manifest as motor disorders affecting balance and physical capacity, and non-motor symptoms such as cognitive decline and mood disorders. People with PD face considerable difficulties coping with associated physical and psychological changes that affect their quality of life. The main form of treatment is pharmacological, which alleviates some of the symptoms but does not slow the progression of the disease. Creatine monohydrate $(\mathrm{Cr})$ may have therapeutic benefits in conditions where energy dysfunction and high rates of apoptosis are present. $\mathrm{Cr}$ supplementation may provide a protective effect by augmenting cytosolic high energy phosphate stores, thereby prolonging the survival of 'at risk' cells of neurodegenerative diseases. Emerging evidence suggests supplementation may offer specific benefits in the treatment of mood disorders associated with PD. Many different types of exercise improve physical capacity, balance, and quality of life. Research has recently demonstrated the potential benefits in PD of diverse modes of exercise, such as aquatic exercise and boxing. Combining exercise with $\mathrm{Cr}$ supplementation can enhance exercise induced muscular strength and power adaptations and may further improve exercise capacity and neuromuscular function. This review will critique evidence relating to the potential efficacy of $\mathrm{Cr}$ supplementation and exercise as a putative therapeutic approach in the treatment of the physiological and psychological challenges presented by PD.
\end{abstract}

Arch Exerc Health Dis 4 (3): 286-298, 2014

Key Words: Parkinson's disease; mood disorders; creatine; supplementation; oxidative stress; exercise training

\section{INTRODUCTION}

Parkinson's disease (PD) is the second most common degenerative neurological disorder after Alzheimer's disease (43). This complex, multi-layered disease has large individual variations in severity and symptoms. The primary pathology involves central dopaminergic neuronal loss, causing distal neurological dysfunction in skeletal muscle (99).

Cardinal motor signs and symptoms manifest as bradykinesia, tremors, rigidity, postural instability, and dyskinesia (79). Co-morbidities, including cognitive decline and depression (86), may be present in $\sim 40$ $50 \%$ of patients; these numbers increase with greater

\footnotetext{
Copyright

C2012 CIAFEL. This is an Open Access article distributed under the terms of the Creative Commons Attribution License (http://creativecommons.org/licenses/by-nc-nd/3.0/deed.en). You are free: to share, to copy, distribute and transmit the work, provided the original author and source are credited.
}

disease severity $(107,125)$ and advanced age at disease onset (104).

The causes of PD are not fully understood; however, environmental toxins and genetic susceptibility are implicated $(28,42)$. Interference with complex I activity of the mitochondrial electron transport chain increases oxidative stress and augments the death of the dopaminergic neurons in the substantia nigra pars compacta $(1,14,43,76,145)$. In addition, there is characteristic accumulation of abnormal proteins known as Lewy Bodies in the surviving neurons (24, $51,64)$. In familial and idiopathic PD conditions, increased accumulation of the protein $\alpha$-synuclein in dopaminergic neurons in the substantia nigra may 
augment apoptosis via an increase in reactive oxygen species (ROS) initiated by endogenous dopamine metabolism (143).

Surface electromyography (EMG) studies demonstrate that people with PD have slower extension movements compared to flexion, whereas individuals without PD show no significant difference between extension and flexion movements (116). Typically, increased and inappropriate co-contraction of agonist and antagonist muscle groups contribute to joint stiffness and rigidity, which results in energy inefficient and impaired movements (92).

Currently, there is no cure for PD: drug therapy is the main line of treatment, which alleviates some of the symptoms but has no effect on the deterioration of the condition over time. Indeed, therapies that slow the progression of this disease have not yet been found. Greater drug doses are required as the disease progresses, but after 5 years of treatment, dyskinesia and 'freezing' episodes worsen in $\sim 40 \%$ of patients (64). The development of adjuvant interventions that could ameliorate the symptoms of PD would represent a major breakthrough.

\section{CREATINE}

Creatine $(\mathrm{Cr})$, or methyl guanidine acetic acid, is a nitrogenous compound synthesized from the amino acids arginine, glycine, and methionine (16). The role of $\mathrm{Cr}$ is pivotal in the transfer of high energy phosphate bonds; it is phosphorylated by the enzyme creatine kinase $(\mathrm{CK})$ to form phosphocreatine $(\mathrm{PCr})$, which can rapidly re-phosphorylate adenosine diphosphate (ADP) to adenosine triphosphate (ATP) (139). This reversible reaction facilitates short duration high intensity muscular activity (25); in addition, Cr shuttles energy from the mitochondria to the cytosol in tissues such as brain and skeletal muscle, which have high and fluctuating energy demands (139). When the demand for energy is very high, rapid hydrolysis of $\mathrm{PCr}$ increases the $\mathrm{Cr}$ concentration of the cytoplasm. $\mathrm{Cr}$ diffuses to the mitochondria through the concentration gradient present in the cytoplasm, where the subsequent interaction of $\mathrm{Cr}$ with mitochondrial $\mathrm{CK}$ is instrumental in up-regulating mitochondrial oxidative phosphorylation (96). Consequently, the importance of $\mathrm{Cr}$ in the regulation of cellular energy metabolism is evident.

An average $70 \mathrm{~kg}$ adult has a total $\mathrm{Cr}$ pool of $\sim 120 \mathrm{~g}$, comprised of $\sim 40 \%$ free creatine and $\sim 60 \% \mathrm{PCr}(46)$. $\mathrm{Cr}$ at a rate of $1-2 \%$, and $\mathrm{PCr}$ at a rate of $6 \%$, are continuously degraded to creatinine by non-enzymatic reactions and excreted in urine (103). Daily replenishment of the total $\mathrm{Cr}$ pool is achieved endogenously via the liver and pancreas $(\sim 1 g)$ and ingested from food sources, predominantly fish and meat $(\sim 1 \mathrm{~g})(15)$.

\section{CREATINE SUPPLEMENTATION}

Supplementation with creatine monohydrate has been used extensively for two decades. A number of studies demonstrate improvements in high intensity short duration exercise, strength, power, and work performed $(30,70,82,90,136)$. The ergogenic effects of supplementation are thought to be from increasing formation of muscle $\mathrm{Cr}$ and $\mathrm{PCr}$ levels (74, 80), leading to improved ATP turnover during intermittent high intensity muscle contraction and accelerated ATP resynthesis during periods of recovery (68). Approximately $20-30 \%$ of individuals do not experience any effects from $\mathrm{Cr}$ supplementation and are referred to as non-responders (69). Non-responders are proposed to be individuals whose muscular $\mathrm{Cr}$ stores are optimal and no further increase is physiologically possible $(67,74)$. However, some studies report no improvement in performance tests despite an increase in intramuscular Cr levels $(60,100$, 124). Wide ranges in study populations, methodologies, and statistical interpretations might contribute to the considerable variation found in response to $\mathrm{Cr}$ supplementation $(53,87)$.

\subsection{Creatine Supplementation as a Therapeutic Agent}

Supplementation may be of greatest benefit to clinical populations in which direct and indirect energy deficits contribute markedly to the pathology of the disease; specifically, conditions featuring neuronal loss, muscle atrophy, and/or fatigue. For example, supplementation has resulted in significantly improved exercise capacity and functional performance in heart failure. Supplementation is rationalised in this disease due to impaired muscle cell metabolism, low oxidative capacity, and a reduction in total creatine content of skeletal muscle; as a result, patients experience exertional fatigue (7). A randomised crossover design with 13 participants taking $20 \mathrm{~g}$ of $\mathrm{Cr}$ per day for $6 \mathrm{wks}$ showed no change in aerobic capacity, anaerobic threshold, or the 6 minute walk test. However, a 15\% increase in elbow flexor muscle strength did occur (91). Furthermore, Gordon et al. (65) reported a 10$20 \%$ increase in leg muscle strength and endurance in heart failure patients after taking a dose of $\mathrm{Cr}$ of $20 \mathrm{~g}$ per day for $1 \mathrm{wk}$. Twenty grams for 5 days significantly increased contractions in the forearm (75\% maximal voluntary contraction), with improvements in muscle metabolism demonstrated by a significant reduction in the formation of ammonia (6). Presently, it is unknown if $\mathrm{Cr}$ supplementation can 
directly influence cardiac performance, but it is suggested that potential for this may be limited (59).

In a cardiac rehabilitation group, no additional benefits were gained from $\mathrm{Cr}$ supplementation in conjunction with exercise. This may in part have been due to the large initial benefits of exercise, which included resistance training, overwhelming the potentially modest additional benefits of $\mathrm{Cr}$ (37). Similarly, no improvement in exercise capacity has been found in $\mathrm{Cr}$ supplemented chronic obstructive pulmonary disease (COPD) rehabilitation $(2,44,61)$ despite improvements in peripheral strength and muscular endurance (61); however, no large scale clinical trials have been conducted.

In idiopathic myopathies, low levels of $\mathrm{PCr}$ and intracellular calcium leakage can exacerbate excitotoxicity (73). Chung et al. (34) reported a placebo controlled 6 month supplementation ( $20 \mathrm{gm} /$ day for 8 days followed by $3 \mathrm{gm} /$ day for the remaining period) in conjunction with a home-based exercise regimen; this improved both the ability to sustain repeated bouts of high intensity exercise (e.g., stair climbing and descent, sit to stand, and walking challenges) and measures of endurance capacity (functional index in myositis). Metabolic myopathies have not shown any beneficial effects from supplementation (87), possibly due to defects in creatine uptake in the muscle (71). Muscle myopathies have many subgroups and phenotypes with high variation in pathology; this presents complex scenarios, particularly as the majority of studies are parallel in design with small participant numbers. Similarly, the effectiveness of $\mathrm{Cr}$ in Amyotrophic lateral sclerosis (ALS) remains under scrutiny. ALS is a progressive neuromuscular disease causing weakness, dysfunctional muscle control, and paralysis. High levels of glutamate in this condition are neurotoxic and cause excitotoxicity, which leads to increased levels of reactive oxygen species. Resulting free radical damage augments oxidative damage and contributes to mitochondrial dysfunction; subsequently, motor neurons die, leading to progressive muscle weakness (26). Other neurodegenerative conditions, such as HD and PD, also feature these characteristics (32). A review by Ellis et al. (89) examined the findings of animal and clinical research into $\mathrm{Cr}$ supplementation in ALS. The authors found that, despite problems with recruitment, study design, and inconclusive results regarding effectiveness, $\mathrm{Cr}$ does show potential to protect vulnerable neurons and improve physical ability.

In Chung's (34) study, exercises were home-based and resulted in improvements in functional activities; whereas in Cornelissen's (37) cardiac rehabilitation study, physical measurement outcomes consisted of a graded cycle test and isometric and isokinetic knee extension strength and endurance. A study comparing exercise and supplementation with exercise alone in PD patients found that although knee extension strength improved similarly in both groups, only the $\mathrm{Cr}$ group improved in the functional sit to stand test (75). This highlights the impact study design variations can have on findings and suggests functional measures of physical performance should be included in testing parameters in non-athletic and clinical populations.

The benefits of supplementation may extend beyond enhancements in skeletal muscle performance. Brain function, such as memory accumulation and recall, is energy dependant (106). As such, Cr supplementation may be beneficial in conditions of increased metabolic demand; for example, in the aging brain (101). Improvements in simple cognitive performance tests in the elderly occurred after $20 \mathrm{~g}$ of $\mathrm{Cr}$ per day for 2 weeks (101). The authors hypothesised that reductions in excitotoxicity and increased neuroprotection may have facilitated these improvements. Furthermore, depressive states have responded favourably to supplementation [see section 4.1] $(4,71,118)$.

The effects of $\mathrm{Cr}$ in Huntington's disease (HD) are equivocal at present. Animal models of $\mathrm{Cr}$ supplementation show improvements in brain atrophy, reductions in intranuclear inclusions $(5,45,58)$, and biomarkers of HD pathology (144). Despite these encouraging findings, clinical trials have found no changes in disease status (137); however, administration of 8-10 weeks of $\mathrm{Cr}$ supplementation did result in a reduction in glutamate and glutamine in the brain of HD patients. This suggests $\mathrm{Cr}$ may reduce levels of excitotoxicity, which are abnormally high in HD, warranting further investigation (17). The CREST-E clinical trial currently underway in the U.S. is evaluating the safety, tolerability, and effectiveness of large doses (up to $40 \mathrm{~g} /$ day) in slowing the progression of functional decline in HD.

Despite variable results, and at times speculative theories surrounding the potential therapeutic benefits of $\mathrm{Cr}$ supplementation in clinical populations, a number of conditions, particularly those featuring high levels of oxidative stress, vulnerable neurons, and energy depletion, may benefit from $\mathrm{Cr}$ supplementation.

\subsection{Creatine Supplementation and Neurodegenerative Disease}

The brain accounts for $2 \%$ of total body mass, whilst using $20 \%$ of its total resting energy output (72). $\mathrm{Cr}$ is required to meet high energy demands; mental retardation and neurological dysfunction may develop in conditions of significant $\mathrm{Cr}$ deficiency (6). Many neurodegenerative conditions share similar 
biochemical pathological characteristics, including energy dysfunction and depletion, increased oxidative stress, excitotoxicity, and mitochondrial dysfunction. Mitochondrial dysfunction appears to play a central role in some of the most common neurodegenerative diseases (43), leading to abnormally high rates of apoptosis (1) and accelerating loss of specific neurons (13).

Exogenous supplementation may increase endogenous $\mathrm{Cr}$ levels and provide greater energy supply to cells by augmenting cytosolic high-energy phosphate stores, thereby exerting a protective effect and prolonging the survival of 'at risk' cells (27). Cerebral creatine deficiency disorders (CCDs), such as X-linked creatine transporter deficiency (SLC6A8 deficiency), which causes mental retardation, speech and language delay, and epilepsy, highlight both the importance of adequate $\mathrm{Cr}$ levels in the brain and the central role of the creatine transporter in maintaining $\mathrm{Cr}$ levels in the CNS (126). Clearly, this transport system will be saturable and so the scope for exogenous supplementation may be limited in situations where no $\mathrm{Cr}$ deficiency is present but such supplementation would at least ensure saturation of the transport system. Studies have shown that an increase in brain $\mathrm{Cr}$ level is possible following supplementation (3).

Whether or not creatine has a direct effect on the pathology of PD is unknown. More likely, it exerts its influence via enhanced bioenergetics, helping make cells more resilient to damaging environments. $\mathrm{Cr}$ supplementation may, therefore, extend the survival of cells; however, progression of the neurodegenerative disease will likely still occur $(27,142)$. As yet unknown is whether or not long term $\mathrm{Cr}$ supplementation down-regulates endogenous $\mathrm{Cr}$ synthesis.

\subsection{Creatine as an Adjuvant Therapy in Parkinson's Disease}

In vitro and animal studies demonstrate the neuroprotective capacity of $\mathrm{Cr}$ supplementation against neurotoxicity $(88,98)$ and the attenuation of motor symptoms in models of PD (133). Animal studies have generated potentially promising data; however, species-related differences make extrapolation of results from animal models to meaningful clinical improvements in humans complex. Bender and colleagues (18) conducted a 2 year, double-blind, placebo-controlled pilot study with 60 PD subjects (Hoehn and Yahr Scale $\leq 2.5$ ). Subjects were supplemented with $20 \mathrm{~g}$ of $\mathrm{Cr}$ per day or placebo for 6 days, followed by $2 \mathrm{~g}$ per day for 6 months and $4 \mathrm{~g}$ per day for the remainder of the 2 year period. Single-photon emission computed tomography (SPECT) was used to measure the extent and degree of dopaminergic nerve cell loss from baseline to the end of the study period. Supplementation was well tolerated by the subjects in the $\mathrm{Cr}$ group; however, it had no significant effect on SPECT variables or total Unified Parkinson's Disease Rating Scale (UPDRS) scores when compared to the placebo group. Importantly, a significant effect $(\mathrm{P}=0.046)$ occurred in the UPDRS subscale 'depression' in the Cr group, suggesting a positive improvement in mood state as a result of supplementation. The $\mathrm{Cr}$ group also had a significantly $(\mathrm{P}<0.05)$ smaller dose increase in dopaminergic therapy at the end of the trial (18), which implies a possible benefit to disease status that may not have been detected by the techniques used in this study.

A randomized, double blind, futility clinical trial in early $\mathrm{PD}$ assessed the ability of $\mathrm{Cr}$ to alter the progression of $\mathrm{PD}$ relative to a pre-determined threshold. Subjects ingested 2 x $5 \mathrm{~g} \mathrm{Cr}$ or placebo per day and a baseline UPDRS score was recorded and reevaluated at $1,3,6$, 9, and 12 months. The mean change in disease status for the $\mathrm{Cr}$ group from baseline to either 12 months or the commencement of symptomatic treatment was 5.6 (SD 8.69); this was lower than the pre-determined threshold value of 7.46 (30\% less than the expected change). As a result, $\mathrm{Cr}$ supplementation could not be rejected as futile. Supplementation was well tolerated by the subjects with $91 \%$ compliance, and none reported serious side effects (132).

Subsequently, a Phase III clinical trial by The National Institute of Neurological Disorders and Stroke Exploratory Trials in Parkinson's Disease (NINDS NET-PD) commenced in 2007 (21). The aim of this study was to evaluate the efficacy of $\mathrm{Cr}$ supplementation $(10 \mathrm{~g} /$ day $)$ in a cohort $(\mathrm{n}=1741)$ of individuals in the early stages of PD, who had been receiving dopaminergic treatment $\leq 2$ years. The primary outcome measurement was to determine if 5 years of $\mathrm{Cr}$ supplementation slows the progression of $\mathrm{PD}$ to a greater degree than standard drug therapy alone. In addition, the safety and tolerability of longterm supplementation would be assessed.

A Global Statistical Test (GST) model was applied in September 2013 by the researchers to determine the efficacy of the $\mathrm{Cr}$ treatment in reducing overall changes in disease state. This was necessary to justify continuation of the clinical trial. The analysis found no significant difference between the treatment and placebo groups. A finding of futility was declared and the trial was terminated (105). In other words, 5 years of supplementation statistical testing suggested that no significant difference in disease progression existed between the treatment and placebo groups. The five measure GST model selected encompasses overall disease status changes. This increases the power of detection when any treatment effect occurs across all measurement domains; however, power is lost if a 
single measure demonstrates change. Under such conditions differences may not be detected, and individual aspects of the efficacy of supplementation could be present but not be detected (81).

Although this finding is disappointing, this study crucially provides important information regarding the tolerability and safety of long term $\mathrm{Cr}$ supplementation in PD. Evidence from animals studies suggests that there are relatively low concentrations of creatine transporters in the substantia nigra area of the brain, which could limit the potential for $\mathrm{Cr}$ to slow the progression of the disease (97). Future publication of the full findings of this clinical trial should inform other studies examining $\mathrm{Cr}$ supplementation in neurological disorders.

\subsection{Antioxidant Effects of Creatine}

Free radicals and reactive oxygen species can impair protein turnover (113) and augment muscle fatigue (93). In vivo experiments suggest $\mathrm{Cr}$ may have antioxidant properties (93), thereby providing some level of protection from the deleterious effects of increased levels of oxidative stress and fatigue associated with PD (62). Cr may augment antioxidant and neuroprotective effects by enhancing cytosolic high energy phosphates that maintain ATP levels under high oxidative stress conditions (130) (see Figure 1).

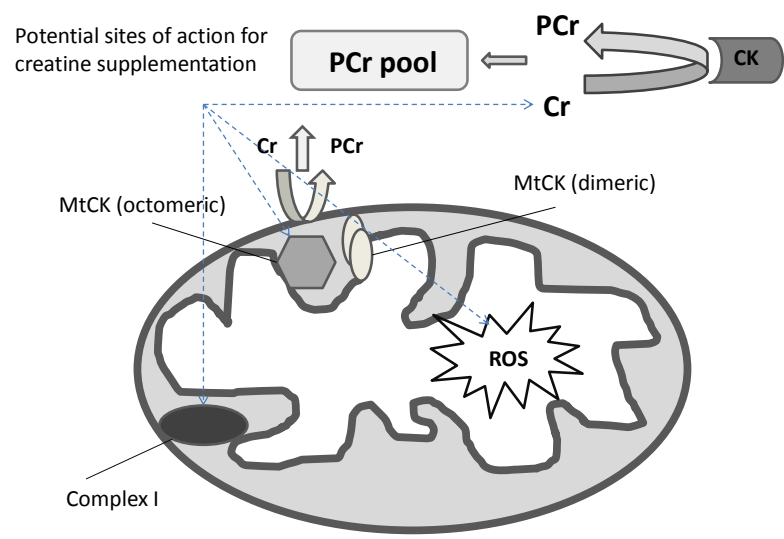

Figure 1: Mitochondrial dysfunction in Parkinson's Disease. Adapted from Adhihetty and Beal. Creatine and its potential therapeutic value for targeting cellular energy impairment in neurodegenerative diseases. Neuromolecular Medicine 2008; 10 p23 Fig.3. Springer/Kluwer Academic Publishers with kind permission of Springer Science and Business Media (12).

Kingsley et al. (84) reported that supplementation in conjunction with 5 days of endurance exercise in healthy males had no effect on oxidative stress levels. However, Bloomer et al. (22) reported 8 weeks of resistance training reduced oxidative stress in subjects with PD. Endurance exercise cannot be directly compared to resistance training; however, this study provides evidence that the oxidative status of people with PD can be altered and suggests a longer time frame may be necessary to observe adaptations. The effect of supplementation on oxidative status in human PD trials has not been evaluated.

\subsection{Creatine and Musculoskeletal Abnormalities in Parkinson's Disease}

Motor dysfunction is primarily related to central dopamine depletion; however, histological studies suggest pathology may not be restricted to the brain (141). Individuals with PD can also have musculoskeletal mitochondrial abnormalities, inflammatory myopathies, and necrotizing myopathies with no obvious link established between these pathologies and adverse drug side effects $(63,141)$. Therefore, increased free radical damage in PD may have a direct effect on skeletal muscle mitochondria (141).

A reduced capacity for muscle torque and force production associated with a prolonged muscle relaxation time (36) and lower levels of EMG activity during isometric voluntary contractions (119) are common in PD. Longer EMG relaxation times have been linked to more pronounced bradykinesia (66). Whether extended muscle relaxation time is directly related to the pathology of the disease or due to drug related side effects is unknown.

Five days of $\mathrm{Cr}$ supplementation improved neuromuscular function in moderately trained healthy men (12). Peak torque (PT) increased 33.4\% (P < $0.05)$ more in the $\mathrm{Cr}$ group than in the placebo group, whilst time to reach $\mathrm{PT}$ in the $\mathrm{Cr}$ group decreased $54.7 \%(\mathrm{P}<0.05)$ more than the placebo group. Measured maximal torque was significantly increased at the highest angular velocities $(1800 \cdot \mathrm{s}-1$ and $240 \mathrm{o} \cdot \mathrm{s}-$ 1). Conduction velocity increased $15 \%(\mathrm{P}<0.05)$ in the $\mathrm{Cr}$ group at all velocities, remaining unchanged in the placebo group, and with no changes reported in measures of fatigue in either group (12).

Supplementation has been shown to decrease muscle relaxation periods in healthy individuals during isometric contractions (134). A decrease in muscle relaxation time may reduce energy expenditure, reduce co-contraction activity, and increase cross-bridge cycling efficiency, potentially improving muscle power during rapid repetitive maximal muscle contractions with no pause between contractions (134). The proposed mechanism for decreased muscle relaxation time is via an improvement in calcium $(\mathrm{Ca} 2+)$ kinetics, enhancing muscle contractile properties $(12,134)$ (see Figure 2). There may be 
potential for $\mathrm{Cr}$ to improve neurological function in individuals with PD; however, to date no studies evaluating the effect of $\mathrm{Cr}$ on neurological function in PD have been published.

Interestingly, although considered a pathological manifestation in $\mathrm{PD}$, prolonged muscle relaxation time is regarded as a mechanism that delays fatigue during isometric contractions in healthy muscle (96). In PD, this may be an adaptive condition that paradoxically results in energy inefficient states during dynamic movements, whilst fatigue in postural muscles is reduced.

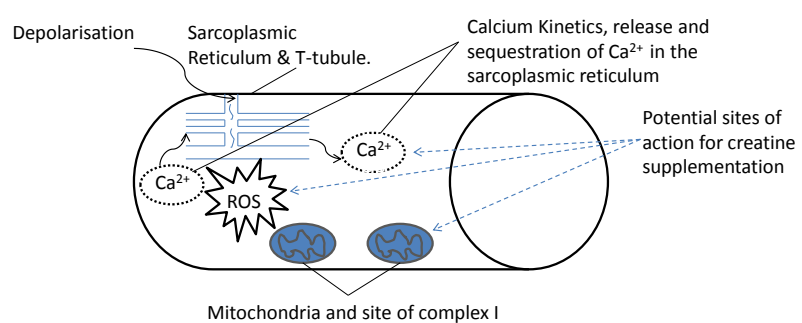

Figure 2: Muscle Cell and Potential Sites of Action for Creatine Supplementation. Adapted from Powers et al. Reactive oxygen and nitrogen species as intracellular signals in skeletal muscle, The Journal of Physiology 2011; 589, with kind permission of John Wiley and Sons (113).

\section{MOOD DISORDERS IN PARKINSON'S DISEASE}

Mood disorders affect most people with PD at some stage in the progression of the disease, the most prevalent being depression, anxiety, and apathy (127). Depression is considered to be the most common mood disorder symptom in PD (39), with an incidence of $\sim 35 \%$; however, this figure may be as high as $90 \%$ in some sub-groups (49). Silverman and Henry (122) propose similarities between common symptoms in PD and those of depression; e.g., slowness in movement, blank expression, stooped posture, and slowness in cognitive function could lead to overdiagnosis of depression. In contrast, other authors suggest these similarities may lead to confusion and a prevalence of underdiagnosis (121). Subtle symptomatic differences in PD patients and nonParkinson's populations diagnosed with clinical depression mean that the use of valid assessment tools are essential when investigating depression in PD. Additionally, depression in PD is often accompanied by anxiety disorder (140). The prevalence of anxiety in $\mathrm{PD}$ is estimated between 40-60\% (115); cognitive dysfunction and anxiety are not related in PD. Approximately $17-70 \%$ of individuals with PD have symptoms of apathy (111). Those with this condition experience low motivation, lethargy, difficulty completing tasks, and a high incidence of fatigue
(127). The incidence of apathy can be related to depression, but can also occur independently (85).

Disease status is related to the presence of clinical depression in PD (110). Impairment of activities of daily living (ADL) is more strongly associated with depression than specific motor symptoms (129), meaning the overall impact the disease has on an individual's quality of life and well-being presents the greatest difficulty. This is closely related to the person's own perception of having poor health and low quality of life; in fact 'illness belief' can predict psychological outcomes in PD (123).

The causes of mood disorders in PD are not completely understood; they are thought to result from a complex interaction between psychological and neurobiological processes (127). An organic origin is evidenced by early presentation of symptoms in a significant number of individuals long before manifestation of motor symptoms and diagnosis of PD (77). Genetic variations in a serotonin transporter gene implicate inherited aspects of PD mood disorders in some individuals (102). Defects in the neurocircuitry (110) of the frontal subcortical region of the brain in neurodegenerative diseases are linked to neuropsychiatric symptoms that may be directly or indirectly implicated in mood disorders (23). These neurological abnormalities in PD are hypothesized as being linked to dysfunctional neurotransmitters of the dopaminergic, serotonergic, and noradrenergic systems (127).

\subsection{Creatine Supplementation and Mood Disorders in Parkinson's Disease}

Recent intriguing evidence examining the potential effects of $\mathrm{Cr}$ supplementation in a number of psychiatric conditions may signal benefits for PD that have not yet been fully realized. A topical review of $\mathrm{Cr}$ metabolism in psychiatric disorders suggests the effect of psychological stress in some of the most common mental health conditions, resulting in augmented energy demands within the brain. This may lead to depletion of total $\mathrm{Cr}$ and $\mathrm{PCr}$ in the brain and subsequent mitochondrial dysfunction, triggering a cascade of neurological events that could cause, or exacerbate, thought or mood disturbances.

Emerging evidence suggests neurons may be vulnerable to damage in conditions of energy imbalance and result in increased oxidative stress. Indeed, production of neurotransmitters such as dopamine and serotonin may be compromised when there is an energy deficit (3). The implications in PD are evident.

Allen (3) examined the potential benefits of $\mathrm{Cr}$ supplementation in psychiatric conditions such as depression and some anxiety disorders. Two weeks of $\mathrm{Cr}$ supplementation increased brain concentrations of 
$\mathrm{Cr}$ and $\mathrm{PCr}(20,95)$ and may have had the potential to improve brain energetics. Enhanced brain metabolism could protect vulnerable neurons associated with mood and emotion, which may be at risk in psychologically stressful conditions present in PD. In addition, $\mathrm{Cr}$ supplementation may help optimize neurotransmitter production, which would be beneficial in depleted states. These theories may explain the findings of Bender and co-workers (18), who reported an improvement in depression scores following $\mathrm{Cr}$ supplementation without an overall improvement in disease status. Recently, individuals with PD suffering from depression benefited from supplementation with omega -3 fish oils (39). This is encouraging as it provides evidence that people with PD respond positively to nutritional supplementation targeted to improve mood disorders.

\section{EXERCISE AND PARKINSON'S DISEASE}

Physical activity levels are likely to be reduced in individuals with PD compared to individuals without PD due to lower exercise capacity related to metabolic inefficiency and earlier onset of fatigue (9). Inactivity contributes to increasing disease severity, poor walking performance, and more difficulty performing the activities of daily life (135). Individuals with PD who experience the highest levels of fatigue tend to be the most sedentary and possess lower levels of functional capacity and physical function (62). Sedentary lifestyles are also linked to increased ROS production (38), immunosuppression, pathological inflammatory conditions, and accelerated brain aging (10). A complete understanding of the potential benefits of exercise in brain health is emerging (8). Erickson et al. (56) reported that moderate intensity aerobic exercise 3 days per week for 1 year increased hippocampal volume by $2 \%$ in adults without dementia compared to a control group who only performed stretching exercises. Increased hippocampal volume is associated with higher serum levels of brain derived neurotrophic factor (BDNF), which mediates neurogenesis in the brain and usually declines with age (56). Evidence suggests that exercise may elevate dopamine receptor expression in PD (138) and may reduce overall levels of skeletal muscle ROS, despite increased ROS production in muscle fibres as a result of contraction (38).

Dynamic, functional, high intensity movements with many repetitions and increasingly complex movements have successfully increased the UPDRS score of 20 patients with mild to moderate PD by a clinically significant mean of 5.05 (52). Exercise training improves strength, balance, and functional capacity and can enhance QOL in individuals with PD $(47,48,52,57,120)$. Better QOL in PD is associated with increased fitness levels, improved social interactions, and greater independence (11).

A variety of exercise modalities are well tolerated by people with PD. These include high intensity resistance $(47,48)$ and aerobic training $(19,78)$. Recently, more diverse types of exercise have shown efficacy in PD. Tai Chi (94), aquatic exercise (11), and boxing training (35) have improved balance, functional capacity, and ADL. Music therapy has also had positive effects in measures of motor and nonmotor symptoms $(50,109)$. Low expectations of any worthwhile benefits from exercise contribute to poor engagement in exercise participation (54) and levels of self-efficacy predict whether or not ambulatory individuals with PD engage in exercise (55). The fear of falling is one of the main barriers to exercise reported by people with PD (54); appropriate aquatic exercise may increase exercise choice and reduce the fear of falling. Longitudinal information regarding adherence to exercise in PD from early in the disease to later stages is not available, but the information available suggests it is crucial to design exercise interventions that offer a variety and choice to meet the various physical and psychological needs of those with PD.

\subsection{Exercise and Creatine Supplementation in Parkinson's Disease}

$\mathrm{Cr}$ supplementation can allow more work to be performed during high intensity repetitive exercise $(30,31,70)$, increase exercise induced muscular strength and power adaptations $(33,40)$, and augment lean body mass (136). Combining strength training and creatine supplementation up-regulates myogenic activity in skeletal muscle and may optimize muscle fibre growth more than strength training alone (108). Additionally, exercise can augment $\mathrm{Cr}$ accumulation in exercised skeletal muscle (74), possibly by enhancing the $\mathrm{Na}+-\mathrm{Cr}$ transporter system (117). To date there have been no studies published evaluating the effect of exercise on brain concentrations of $\mathrm{Cr}$.

Currently one study has measured the effect of $\mathrm{Cr}$ supplementation and exercise in PD. Hass et al. (75) combined supplementation with resistance training in a randomized, double-blind study of twenty subjects (n $=17$ males, $\mathrm{n}=3$ females) classified as the Hoehn and Yahr scale $\leq 3$. Subjects performed one set of 8-12 reps at $70 \%$ of $1 \mathrm{RM}$ for the upper and lower body to volitional fatigue for 12 weeks; in addition, subjects performed one set of leg extension and flexion at 50\% of 1RM, which allows faster movements to be performed. Load was progressively increased by 5 $10 \%$ when subjects were able to perform 12 reps during strength training, and 20 reps for low resistance power training. Post exercise chest press, leg 
extension, and bicep curls increased 9\%, 16\%, and $18 \%$, respectively, in the placebo group, and $21 \%$, $18 \%$, and $23 \%$, respectively, in the $\mathrm{Cr}$ group. Both groups significantly improved leg extension endurance $(\mathrm{P} \leq 0.05)$ and increased fat-free mass $(\mathrm{P}=0.002)$; no significant differences were found between groups (75).

Combining resistance training and supplementation improved muscular strength and endurance compared to resistance training alone. Despite an increase in leg extension strength, in both groups only the $\mathrm{Cr}$ group significantly improved the chair stand test. Supplementation may have had a greater effect in the chair stand test as this test involves repeated high intensity movements. In the $\mathrm{Cr}$ supplemented group, neurological function as well as strength may have been improved.

$\mathrm{Cr}$ supplementation - in conjunction with different types and intensities of exercise - may augment the benefits of exercise alone (see Figure 3). Performing high intensity exercise such as boxing, aquatic resistance training, deep-water running, or aquatic cycling with supplementation may improve training effects, which would be transferred to improvements in QOL and ADL in PD. Ultimately, real improvement in a person's quality of life is the most important aspect, both to PD patients and to their caretakers.

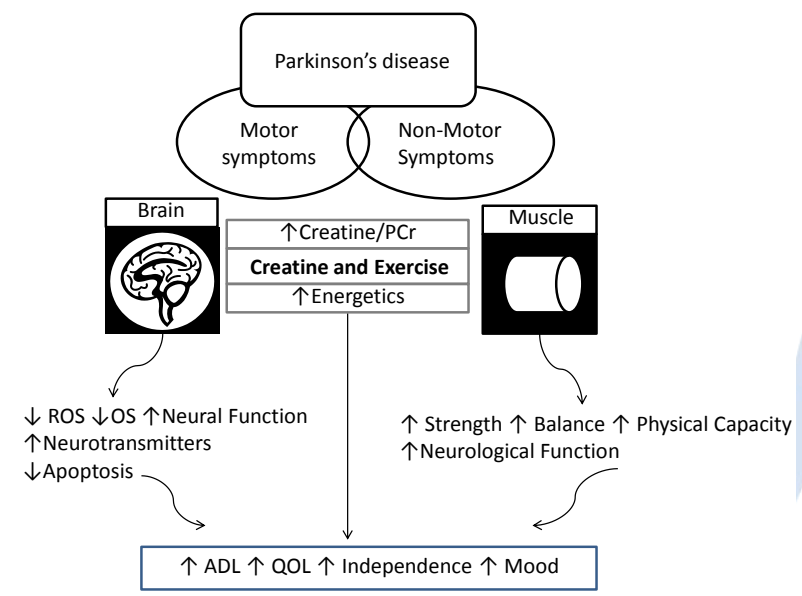

Figure 3: Potential Synergistic Relationship between Exercise and Creatine Supplementation in Parkinson's Disease. Reactive Oxygen Species (ROS). Oxidative Stress (OS). Activities of Daily Living (ADL). Quality of Life (QOL).

\section{SAFETY OF ORAL CREATINE SUPPLEMETATION}

No serious adverse effects have been documented as a result of short term supplementation $(29,37,41,75$, 87 ), or long term studies of up to 2 years duration (17, $71,90,132)$, in healthy and clinical populations.
The most consistently reported side effect of supplementation is weight gain of $1-2 \mathrm{~kg}$, which is attributed to an increase in intracellular water in muscle tissue (80). In an extensive review of safety issues and concerns by Wyss et al. (142), evidence of muscle cramps, increased thirst, stomach cramps, diarrhoea, and rashes have been isolated cases and subjective reports. Reports of renal dysfunction linked to supplementation have been confined to case studies (114, 128, 131). In Pritchard et al. (114) subjects had a previous history of renal dysfunction, whilst the subject in Thorsteinsdottir et al. (131) had consumed multiple supplements in addition to creatine. The affected person in Taner et al. (128) had no prior renal problems, nor had they reported consuming any other supplements; on cessation of supplementation renal function returned to normal. Individual case studies should not be dismissed, but they lack controls that would provide more conclusive evidence. A recent comprehensive review concludes $\mathrm{Cr}$ supplementation does not impair glomerular filtration rate or glomerular membrane permeability in healthy or neurodegenerative subjects (83). Nevertheless, individuals who may have existing renal disease, or an increased risk of kidney dysfunction, should be regularly monitored $(83,112)$.

\section{CONCLUSION}

Parkinson's disease presents a challenging scenario for those directly affected. Additionally, it presents complex demands for the scientific community, supporting professionals in their quest to elucidate the aetiology of the disease and devise the best prevention and treatment strategies. The individual variability of the condition and multi-layered symptomatology determines that a holistic approach is required.

$\mathrm{Cr}$ is central to the transfer of energy bonds in tissues with highenergy requirements. Many neurodegenerative diseases, including Parkinson's disease, demonstrate electron pathway pathologies that are possible targets for the pleiotropic effects of Cr. In vitro and animal models of PD demonstrate that $\mathrm{Cr}$ has neuroprotective effects, and clinical trials suggest a promising impact on mood and disease state. Exogenous $\mathrm{Cr}$ may augment cytosolic high energy phosphate stores, thereby rendering vulnerable cells more resistant to environmental stress and prolonging their life. The highly specialized energy buffering capacity of $\mathrm{Cr}$ may protect brain cells from the deleterious effects of stressful mood disorders, which have been found to deplete endogenous brain $\mathrm{Cr}$ concentrations. Energy deficiency in specialized brain cells may lead to increased oxidative stress conditions and reductions in neurotransmitter production. Supplementation with omega-3 fatty acids has been found to improve depression in PD patients, 
demonstrating potential efficacy for nutritional supplementation strategies in this condition. It is hypothesized here that $\mathrm{Cr}$ supplementation may offer benefits in the treatment of mood disorders in PD.

Additionally, the ergogenic effects of supplementation may improve functional capacity, reduce muscle atrophy, and be of specific benefit to PD sufferers. Individuals with $\mathrm{PD}$ have demonstrated energy inefficient and impaired movements associated with longer relaxation times. Musculoskeletal mitochondrial abnormalities, inflammatory, and necrotizing myopathies may also present. Supplementation may improve muscle efficiency and neuromuscular function by up-regulating $\mathrm{Ca} 2+$ kinetics and enhancing muscle contractile properties. A variety of exercise modalities improves functional capacity and quality of life in individuals with PD. Greater exercise options should help address particular problems associated with engagement in exercise. Combining supplementation with exercise may have synergistic effects by accelerating $\mathrm{Cr}$ uptake and augmenting the beneficial effects of exercise alone. No serious safety issues have been associated with creatine supplementation; however, a greater understanding of the optimal application of supplementation is necessary to realize the full potential of this nutritional supplement.

Further, well controlled studies are required to investigate the potential effects of $\mathrm{Cr}$ supplementation in mood disorders and assess the combined effects of supplementation and exercise on functional capacity and QOL in people with PD.

This review concludes that creatine supplementation, particularly in conjunction with exercise, presents the potential for a safe, inexpensive, and effective adjuvant treatment that may improve quality of life in PD.

\section{REFERENCES}

1. Adhihetty PJ and Beal MF. Creatine and its potential therapeutic value for targeting cellular energy impairment in neurodegenerative diseases. Neuromolecular Medicine 10: 275 290,2008

2. Al-Ghimlas F and Todd DC. Creatine supplementation for patients with copd receiving pulmonary rehabilitation: A systematic review and meta-analysis. Respirology 15: 785-795, 2010.

3. Allen PJ. Creatine metabolism and psychiatric disorders: Does creatine supplementation have therapeutic value? Neurosci Biobehav Rev 36: 1442-1462, 2012.

4. Amital D, Vishne T, Rubinow A, and Levine J. Observed effects of creatine monohydrate in a patient with depression and fibromyalgia. Am J Psychiat 163: 1840-1841, 2006.

5. Andreassen OA, Dedeoglu A, Ferrante RJ, Jenkins BG, Ferrante KL, Thomas M, Friedlich A, Browne SE, Schilling G, Borchelt DR, Hersch SM, Ross CA, and Beal MF. Creatine increases survival and delays motor symptoms in a transgenic animal model of huntington's disease. Neurobiol Dis 8: 479-491, 2001.
6. Andres RH, Ducray AD, Schlattner U, Wallimann T, and Widmer HR. Functions and effects of creatine in the central nervous system. Brain Research Bulletin 76: 329-343, 2008.

7. Andrews R, Greenhaff P, Curtis S, Perry A, and Cowley AJ. The effect of dietary creatine supplementation on skeletal muscle metabolism in congestive heart failure. European Heart Journal 19: 617-622, 1998.

8. Ang E-T, Tai Y-K, Lo S-Q, Seet R, and Soong T-W Neurodegenerative diseases: Exercising toward neurogenesis and neuroregeneration. Front Aging Neurosci 2, 2010.

9. Archer T, Fredriksson A, and Johansson B. Exercise alleviates parkinsonism: Clinical and laboratory evidence. Acta Neurologica Scandinavica 123: 73-84, 2011 a.

10. Archer T, Fredriksson A, Schutz E, and Kostrzewa RM Influence of physical exercise on neuroimmunological functioning and health: Aging and stress. Neurotoxicity Research 20: 69-83, 2011 b.

11. Ayán $\mathrm{C}$ and Cancela $\mathrm{J}$. Feasibility of 2 different water-based exercise training programs in patients with parkinson's disease: A pilot study. Archives of Physical Medicine and Rehabilitation 93: 1709-1714, 2012

12. Bazzucchi I, Felici F, and Sacchetti M. Effect of short-term creatine supplementation on neuromuscular function. Med Sci Sports Exerc 41: 1934-1941, 2009.

13. Beal M. Neuroprotective effects of creatine. Amino Acids 40: 1305-1313, 2011

14. Beal MF. Therapeutic approaches to mitochondrial dysfunction in parkinson's disease. Parkinsonism Relat Disord 15 Suppl 3: S189-194, 2009.

15. Bemben $\mathrm{MG}$ and Lamont HS. Creatine supplementation and exercise performance - recent findings. Sports Med 35: 107-125, 2005

16. Bemben MG and Lamont HS. Creatine supplementation and exercise performance: Recent findings. Sports Med 35: 107-125, 2005.

17. Bender A, Auer DP, Merl T, Reilmann R, Saemann P, Yassouridis A, Bender J, Weindl A, Dose M, Gasser T, and Klopstock T. Creatine supplementation lowers brain glutamate levels in huntington's disease. J Neurol 252: 36-41, 2005.

18. Bender A, Koch W, Elstner M, Schombacher Y, Bender J, Moeschl M, Gekeler F, Muller-Myhsok B, Gasser T, Tatsch K, and Klopstock T. Creatine supplementation in parkinson disease: A placebo-controlled randomized pilot trial. Neurology 67: 12621264, 2006.

19. Bergen JL, Toole T, Elliott Iii RG, Wallace B, Robinson K, and Maitland CG. Aerobic exercise intervention improves aerobic capacity and movement initiation in parkinson's disease patients. NeuroRehabilitation 17: 161-168, 2002.

20. Bianchi MC, Tosetti M, Fornai F, Grazia Alessandri M, Cipriani $\mathrm{P}$, De Vito G, and Canapicchi R. Reversible brain creatine deficiency in two sisters with normal blood creatine level. Ann Neurol 47: 511-513, 2000.

21. Bloom MZ. Nih announces phase iii clinical trial of creatine for parkinson's disease. The Consultant pharmacist 22: 378, 2007.

22. Bloomer R, Schilling B, Karlage R, Ledoux M, Pfeiffer R, and Callegari J. Effect of resistance training on blood oxidative stress in parkinson disease. Med Sci Sports Exerc 40: 1385-1389, 2008.

23. Bonelli RM and Cummings JL. Frontal-subcortical circuitry and behavior. Dialogues in clinical neuroscience 9: 141, 2007.

24. Braak H, Rub U, and Del Tredici K. Involvement of precerebellar nuclei in multiple system atrophy. Neuropathol Appl Neurobiol 29: 60-76, 2003.

25. Brancaccio P, Maffulli N, and Limongelli FM. Creatine kinase monitoring in sport medicine. British Medical Bulletin 81-82: 209-230, 2007.

26. Britton D, Cleary S, and Miller R. What is als and what is the philosophy of care? Perspectives on Swallowing \& Swallowing Disorders (Dysphagia) 22: 4-11, 2013. 
27. Brustovetsky N, Brustovetsky T, and Dubinsky JM. On the mechanisms of neuroprotection by creatine and phosphocreatine. J Neurochem 76: 425-434, 2001.

28. Calne DB and Langston JW. Etiology of parkinsons-disease. Lancet 2: 1457-1459, 1983.

29. Cancela P, Ohanian C, Cuitino E, and Hackney AC. Creatine supplementation does not affect clinical health markers in football players. Br J Sports Med 42: 731-735, 2008.

30. Casey A, Constantin-Teodosiu D, Howell S, Hultman E, and Greenhaff PL. Creatine ingestion favorably affects performance and muscle metabolism during maximal exercise in humans. $\mathrm{Am}$ J Physiol Endocrinol Metab 271: E31-E37, 1996.

31. Casey A and Greenhaff PL. Does dietary creatine supplementation play a role in skeletal muscle metabolism and performance? The American Journal of Clinical Nutrition 72: 607S-617S, 2000

32. Chaturvedi RK and Beal MF. Mitochondria targeted therapeutic approaches in parkinson's and huntington's diseases. $M C N$ : Molecular \& Cellular Neuroscience 55: 101-114, 2013.

33. Chrusch MJ, Chilibeck PD, Chad KE, Davison KS, and Burke DG. Creatine supplementation combined with resistance training in older men. Med Sci Sports Exerc 33: 2111-2117, 2001.

34. Chung YL, Alexanderson H, Pipitone N, Morrison C, Dastmalchi M, Stahl-Hallengren C, Richards S, Thomas EL, Hamilton G, Bell JD, Lundberg IE, and Scott DL. Creatine supplements in patients with idiopathic inflammatory myopathies who are clinically weak after conventional pharmacologic treatment: Six-month, double-blind, randomized, placebocontrolled trial. Arthritis \& Rheumatism-Arthritis Care \& Research 57: 694-702, 2007.

35. Combs SA, Diehl MD, Staples WH, Conn L, Davis K, Lewis N, and Schaneman K. Boxing training for patients with parkinson disease: A case series. Physical Therapy 91: 132-142, 2011.

36. Corcos DM, Chen CM, Quinn NP, McAuley J, and Rothwell JC. Strength in parkinson's disease: Relationship to rate of force generation and clinical status. Ann Neurol 39: 79-88, 1996

37. Cornelissen V, Defoor J, Stevens A, Schepers D, Hespel P, Decramer M, Mortelmans L, Dobbels F, Vanhaecke J, Fagard R, and Vanhees L. Effect of creatine supplementation as a potential adjuvant therapy to exercise training in cardiac patients: A randomized controlled trial. Clin Rehabil 24: 988-999, 2010.

38. Cullen ME, Yuen AHY, Felkin LE, Smolenski RT, Hall JL, Grindle S, Miller LW, Birks EJ, Yacoub MH, and Barton PJR. Myocardial expression of the arginine:Glycine amidinotransferase gene is elevated in heart failure and normalized after recovery. Circulation 114: I-16-I-20, 2006.

39. da Silva TM, Munhoz RP, Alvarez C, Naliwaiko K, Kiss Á, Andreatini R, and Ferraz AC. Depression in parkinson's disease: A double-blind, randomized, placebo-controlled pilot study of omega-3 fatty-acid supplementation. Journal of affective disorders 111: 351-359, 2008.

40. Dalbo VJ, Roberts MD, Lockwood CM, Tucker PS, Kreider RB, and Kerksick CM. The effects of age on skeletal muscle and the phosphocreatine energy system: Can creatine supplementation help older adults. Dynamic medicine : DM 8: 6, 2009.

41. Dalbo VJ, Roberts MD, Stout JR, and Kerksick CM. Putting to rest the myth of creatine supplementation leading to muscle cramps and dehydration. Br J Sports Med 42: 567-573, 2008.

42. de Lau LML and Breteler MMB. Epidemiology of parkinson's disease. Lancet Neurol 5: 525-535, 2006.

43. de Moura MB, dos Santos LS, and Van Houten B. Mitochondrial dysfunction in neurodegenerative diseases and cancer. Environ Mol Mutagen 51: 391-405, 2010.

44. Deacon SJ, Vincent EE, Greenhaff PL, Fox J, Steiner MC, Singh $\mathrm{SJ}$, and Morgan MD. Randomized controlled trial of dietary creatine as an adjunct therapy to physical training in chronic obstructive pulmonary disease. American Journal of Respiratory \& Critical Care Medicine 178: 233-239, 2008.

45. Dedeoglu A, Kubilus JK, Yang L, Ferrante KL, Hersch SM, Beal MF, Ferrante, and Robert J. Creatine therapy provides neuroprotection after onset of clinical symptoms in huntington's disease transgenic mice. Journal of Neurochemistry 85: 13591367,2003

46. Demant TW and Rhodes EC. Effects of creatine supplementation on exercise performance. Sports Med 28: 49-60, 1999.

47. Dibble LE, Hale TF, Marcus RL, Droge J, Gerber JP, and LaStayo PC. High-intensity resistance training amplifies muscle hypertrophy and functional gains in persons with parkinson's disease. Mov Disord 21: 1444-1452, 2006.

48. Dibble LE, Hale TF, Marcus RL, Gerber JP, and LaStayo PC. High intensity eccentric resistance training decreases bradykinesia and improves quality of life in persons with parkinson's disease: A preliminary study. Parkinsonism Relat Disord 15: 752-757, 2009.

49. Dissanayaka NN, O'Sullivan JD, Silburn PA, and Mellick GD Assessment methods and factors associated with depression in parkinson's disease. Journal of the neurological sciences 310: 208-210, 2011.

50. Docu A. Parkinson's disease and influence of music in their rehabilitation. Ovidius University Annals, Physical Education and Sport/Science, Movement and Health Series 12: 469-473, 2012.

51. Duda JE, Lee VMY, and Trojanowski JQ. Neuropathology of synuclein aggregates: New insights into mechanisms of neurodegenerative diseases. J Neurosci Res 61: 121-127, 2000.

52. Ebersbach G, Ebersbach A, Edler D, Kaufhold O, Kusch M, Kupsch A, and Wissel J. Comparing exercise in parkinson's disease-the berlin lsvt (r) big study. Mov Disord 25: 1902-1908, 2010 .

53. Eliot KA, Knehans AW, Bemben DA, Witten MS, Carter J, and Bemben MG. The effects of creatine and whey protein supplementation on body composition in men aged 48 to 72 years during resistance training. J Nutr Health Aging 12: 208212, 2008.

54. Ellis T, Boudreau JK, DeAngelis TR, Brown LE, Cavanaugh JT, Earhart GM, Ford MP, Foreman KB, and Dibble LE. Barriers to exercise in people with parkinson disease. Physical therapy 93: 628-636, 2013.

55. Ellis T, Cavanaugh JT, Earhart GM, Ford MP, Foreman KB, Fredman L, Boudreau JK, and Dibble LE. Factors associated with exercise behavior in people with parkinson disease. Physical therapy 91: 1838-1848, 2011.

56. Erickson KI, Voss MW, Prakash RS, Basak C, Szabo A, Chaddock L, Kim JS, Heo S, Alves H, White SM, Wojcicki TR, Mailey E, Vieira VJ, Martin SA, Pence BD, Woods JA, McAuley E, and Kramer AF. Exercise training increases size of hippocampus and improves memory. Proceedings of the National Academy of Sciences 108: 3017-3022, 2011.

57. Falvo MJ, Schilling BK, and Earhart GM. Parkinson's disease and resistive exercise: Rationale, review, and recommendations. Mov Disord 23: 1-11, 2008.

58. Ferrante RJ, Andreassen OA, Jenkins BG, Dedeoglu A, Kuemmerle S, Kubilus JK, Kaddurah-Daouk R, Hersch SM, and Beal MF. Neuroprotective effects of creatine in a transgenic mouse model of huntington's disease. Journal of Neuroscience 20: 4389-4397, 2000

59. Field ML. Creatine supplementation in congestive heart failure. Cardiovascular Research 31: 174-176, 1996.

60. Finn JP, Ebert TR, Withers RT, Carey MF, Mackay M, Phillips JW, and Febbraio MA. Effect of creatine supplementation on metabolism and performance in humans during intermittent sprint cycling. European Journal of Applied Physiology 84: 238243, 2001.

61. Fuld JP, Kilduff LP, Neder JA, Pitsiladis Y, Lean MEJ, Ward SA, and Cotton MM. Creatine supplementation during pulmonary rehabilitation in chronic obstructive pulmonary disease. Thorax 60: 531-537, 2005.

62. Garber CE and Friedman JH. Effects of fatigue on physical activity and function in patients with parkinson's disease. Neurology 60: 1119-1124, 2003.

63. Gdynia HJ, Sperfeld AD, Unrath A, Ludolph AC, Sabolek M, Storch A, and Kassubek J. Histopathological analysis of skeletal 
muscle in patients with parkinson's disease and 'dropped head'/'bent spine' syndrome. Parkinsonism Relat Disord 15: 633639, 2009.

64. Giroux ML. Parkinson disease: Managing a complex, progressive disease at all stages. Cleveland Clinic Journal of Medicine 74: 313-+, 2007.

65. Gordon A, Hultman E, Kaijser L, Kristjansson S, Rolf CJ, Nyquist $\mathrm{O}$, and Sylén C. Creatine supplementation in chronic heart failure increases skeletal muscle creatine phosphate and muscle performance. Cardiovascular Research 30: 413-418, 1995.

66. Grasso M, Mazzini L, and Schieppati M. Muscle relaxation in parkinson's disease: A reaction time study. Mov Disord 11: 411420, 1996.

67. Green AL, Hultman E, Macdonald IA, Sewell DA, and Greenhaff PL. Carbohydrate ingestion augments skeletal muscle creatine accumulation during creatine supplementation in humans. American Journal of Physiology - Endocrinology And Metabolism 271: E821-E826, 1996.

68. Greenhaff PL. Creatine and its application as an ergogenic aid. Int J Sport Nutr 5: S100-110, 1995.

69. Greenhaff PL, Bodin K, Soderlund K, and Hultman E. Effect of oral creatine supplementation on skeletal muscle phosphocreatine resynthesis. American Journal of Physiology Endocrinology And Metabolism 266: E725-E730, 1994.

70. Greenhaff PL, Casey A, Short AH, Harris R, Soderlund K, and Hultman E. Influence of oral creatine supplementation of muscle torque during repeated bouts of maximal voluntary exercise in man. Clinical Science 84: 565-571, 1993.

71. Gualano B, Artioli G, Poortmans J, and Lancha Junior A. Exploring the therapeutic role of creatine supplementation. Amino Acids 38: 31-44, 2010.

72. Gualano B, Artioli GG, Poortmans JR, and Lancha Junior AH. Exploring the therapeutic role of creatine supplementation. Amino Acids 38: 31-44, 2010.

73. Habers GEA and Takken T. Safety and efficacy of exercise training in patients with an idiopathic inflammatory myopathya systematic review. Rheumatology 50: 2113-2124, 2011.

74. Harris RC, Soderlund K, and Hultman E. Elevation of creatine in resting and exercised muscle of normal subjects by creatine supplementation. Clinical Science 83: 367-374, 1992.

75. Hass CJ, Collins MA, and Juncos JL. Resistance training with creatine monohydrate improves upper-body strength in patients with parkinson disease: A randomized trial. Neurorehabilitation and Neural Repair 21: 107-115, 2007.

76. Hattori N. Etiology and pathogenesis of parkinson's disease: From mitochondrial dysfunctions to familial parkinson's disease. Rinsho Shinkeigaku 44: 241-262, 2004.

77. Hemmerle AM, Herman JP, and Seroogy KB. Stress, depression and parkinson's disease. Experimental Neurology 233: 79-86, 2012.

78. Herman T, Giladi N, Gruendlinger L, and Hausdorff JM. Six weeks of intensive treadmill training improves gait and quality of life in patients with parkinson's disease: A pilot study. Archives of Physical Medicine and Rehabilitation 88: 1154-1158, 2007.

79. Hughes AJ, Daniel SE, and Lees AJ. The clinical-features of parkinsons-disease in 100 histologically proven cases. In: Parkinsons disease : From basic research to treatment, edited by Narabayashi H, Nagatsu T, Yanagisawa N and Mizuno Y. New York: Raven Press, 1993, p. pp 595-599

80. Hultman E, Soderlund K, Timmons JA, Cederblad G, and Greenhaff PL. Muscle creatine loading in men. J Appl Physiol 81: 232-237, 1996.

81. Investigators NN-P. Design innovations and baseline findings in a long-term parkinson's trial: Net-pd 1s-1. Movement disorders: official journal of the Movement Disorder Society 27: 1513, 2012.

82. Kilduff LP, Vidakovic P, Cooney G, Twycross-Lewis R, Amuna P, Parker M, Paul L, and Pitsiladis YP. Effects of creatine on isometric bench-press performance in resistance-trained humans. Med SciSports Exercise 34: 1176-1183, 2002.

83. Kim HJ, Kim CK, Carpentier A, and Poortmans JR. Studies on the safety of creatine supplementation. Amino Acids 40: 14091418,2011

84. Kingsley MIC, Cunningham D, Mason L, Kilduff LP, and McEneny J. Role of creatine supplementation on exerciseinduced cardiovascular function and oxidative stress. Oxidative Medicine and Cellular Longevity 2: 247-254, 2009.

85. Kirsch-Darrow L, Marsiske M, Okun MS, Bauer R, and Bowers D. Apathy and depression: Separate factors in parkinson's disease. Journal of the International Neuropsychological Society 17: 1058-1066, 2011.

86. Klepac N, Hajnsek S, and Trkulja V. Cognitive performance in nondemented nonpsychotic parkinson disease patients with or without a history of depression prior to the onset of motor symptoms. J Geriatr Psychiatry Neurol 23: 15-26, 2010.

87. Kley RA, Tarnopolsky MA, and Vorgerd M. Creatine for treating muscle disorders. Cochrane Database of Systematic Reviews, 2011.

88. Klopstock T, Elstner M, and Bender A. Creatine in mouse models of neurodegeneration and aging. Amino Acids 40: $1297-$ 1303, 2011.

89. Krcitochvil CJ, Greenhill LL, March JS, Burke WJ, and Vaughan BS. The role of creatine in the management of amyotrophic lateral sclerosis and other neurodegenerative disorders. CNS Drugs 18: 967-980, 2004.

90. Kreider RB. Effects of creatine supplementation on performance and training adaptations. Molecular and Cellular Biochemistry 244: 89-94, 2003

91. Kuethe F, Krack A, Richartz BM, and Figulla HR. Creatine supplementation improves muscle strength in patients with congestive heart failure. Pharmazie 61: 218-222, 2006.

92. Latash ML. Neurolophysiological basis of movement (2nd ed.). Leeds: Human Kinetics, 2008, p. p 322 - 326.

93. Lawler JM, Barnes WS, Wu G, Song W, and Demaree S. Direct antioxidant properties of creatine. Biochem Biophys Res Commun 290: 47-52, 2002.

94. Li F, Harmer P, Fitzgerald K, Eckstrom E, Stock R, Galver J, Maddalozzo G, and Batya SS. Tai chi and postural stability in patients with parkinson's disease. New England Journal of Medicine 366: 511-519, 2012.

95. Lyoo IK, Kong SW, Sung SM, Hirashima F, Parow A, Hennen J, Cohen BM, and Renshaw PF. Multinuclear magnetic resonance spectroscopy of high-energy phosphate metabolites in human brain following oral supplementation of creatine-monohydrate. Psychiatry Research: Neuroimaging 123: 87-100, 2003.

96. MacIntosh BR, Gardiner PF, and AJ. M. Skeletal muscle. Form and function. Leeds: Human Kinetics, 2006.

97. Mak CSW, Waldvogel HJ, Dodd JR, Gilbert RT, Lowe MTJ, Birch NP, Faull RLM, and Christie DL. Immunohistochemical localisation of the creatine transporter in the rat brain. Neuroscience 163: 571-585, 2009.

98. Matthews RT, Ferrante RJ, Klivenyi P, Yang L, Klein AM Mueller G, Kaddurah-Daouk R, and Beal MF. Creatine and cyclocreatine attenuate mptp neurotoxicity. Experimental Neurology 157: 142-149, 1999.

99. Mazzio EA, Close F, and Soliman KFA. The biochemical and cellular basis for nutraceutical strategies to attenuate neurodegeneration in parkinson's disease. Int J Mol Sci 12: 506$569,2011$.

100.McKenna MJ, Morton J, Selig SE, and Snow RJ. Creatine supplementation increases muscle total creatine but not maximal intermittent exercise performance. J Appl Physiol 87: 2244-2252, 1999.

101.McMorris T, Mielcarz G, Harris RC, Swain JP, and Howard A. Creatine supplementation and cognitive performance in elderly individuals. Aging Neuropsychology and Cognition 14: 517-528, 2007. 
102. Menza MA, Palermo B, DiPaola R, Sage JI, and Ricketts MH. Depression and anxiety in parkinson's disease: Possible effect of genetic variation in the serotonin transporter. Journal of geriatric psychiatry and neurology 12: 49-52, 1999.

103.Mesa JLM, Ruiz JR, Gonzalez-Gross MM, Gutierrez Sainz A, and Castillo Garzon MJ. Oral creatine supplementation and skeletal muscle metabolism in physical exercise. Sports Med 32: 903-944, 2002.

104.Muslimovic D, Post B, Speelman JD, and Schmand B. Cognitive profile of patients with newly diagnosed parkinson disease. Neurology 65: 1239-1245, 2005.

105.NET-PD. Statement of the termination of net-pd ls-1 study, 2013.

106.Nyberg L, Tulving E, Habib R, Nilsson LG, Kapur S, Houle S, Cabeza R, and McIntosh AR. Functional brain maps of retrieval mode and recovery of episodic information. Neuroreport 7 : 249252, 1995.

107.Oguru M, Tachibana H, Toda K, Okuda B, and Oka N. Apathy and depression in parkinson disease. J Geriatr Psychiatry Neurol 23: 35-41, 2010.

108. Olsen S, Aagaard P, Kadi F, Tufekovic G, Verney J, Olesen JL, Suetta C, and Kjaer M. Creatine supplementation augments the increase in satellite cell and myonuclei number in human skeletal muscle induced by strength training. J Physiol-London 573: 525534, 2006.

109.Pacchetti C, Mancini F, Aglieri R, Fundarò C, Martignoni E, and Nappi G. Active music therapy in parkinson's disease: An integrative method for motor and emotional rehabilitation. Psychosomatic Medicine 62: 386-393, 2000.

110.Piccinni A, Marazziti D, Veltri A, Ceravolo R, Ramacciotti C, Carlini M, Del Debbio A, Schiavi E, Bonuccelli U, and Dell'Osso L. Depressive symptoms in parkinson's disease. Comprehensive Psychiatry 53: 727-731, 2012.

111.Pluck GC and Brown RG. Apathy in parkinson's disease. Journal of Neurology, Neurosurgery \& Psychiatry 73: 636-642, 2002.

112.Poortmans JR and Francaux M. Adverse effects of creatine supplementation: Fact or fiction? Sports Med 30: 155-170, 2000.

113.Powers SK, Talbert EE, and Adhihetty PJ. Reactive oxygen and nitrogen species as intracellular signals in skeletal muscle. $J$ Physiol-London 589: 2129-2138, 2011.

114.Pritchard NR and Kalra PA. Renal dysfunction accompanying oral creatine supplementation. Lancet 351: 1252-1253, 1998.

115.Richard IH. Anxiety disorders in parkinson's disease. ADVANCES IN NEUROLOGY-NEW YORK-RAVEN PRESS- 96: 42, 2005.

116. Robichaud J, Pfann K, Comella C, Brandabur M, and Corcos D. Greater impairment of extension movements as compared to flexion movements in parkinson's disease. Experimental Brain Research 156: 240-254, 2004.

117. Robinson TM, Sewell DA, Hultman E, and Greenhaff PL. Role of submaximal exercise in promoting creatine and glycogen accumulation in human skeletal muscle. J Appl Physiol 87: 598604, 1999.

118.Roitman S, Green T, Osher Y, Karni N, and Levine J. Creatine monohydrate in resistant depression: A preliminary study. Bipolar Disorders 9: 754-758, 2007.

119. Salenius S, Avikainen S, Kaakkola S, Hari R, and Brown P. Defective cortical drive to muscle in parkinson's disease and its improvement with levodopa. Brain 125: 491-500, 2002.

120.Scandalis TA, Bosak A, Berliner JC, Helman LL, and Wells MR. Resistance training and gait function in patients with parkinson's disease. American Journal of Physical Medicine \& Rehabilitation 80: 38-43, 2001.

121. Shulman LM, Taback RL, Rabinstein AA, and Weiner WJ. Nonrecognition of depression and other non-motor symptoms in parkinson's disease. Parkinsonism Relat Disord 8: 193-197, 2002.

122.Silverman F and Henry B. Depression-a primary symptom of parkinson disease. Journal of Rehabilitation 55: 31-33, 1989.
123.Simpson J, Lekwuwa G, and Crawford T. Illness beliefs and psychological outcome in people with parkinson's disease. Chronic Illness 9: 165-176, 2013.

124. Snow RJ, McKenna MJ, Selig SE, Kemp J, Stathis CG, and Zhao S. Effect of creatine supplementation on sprint exercise performance and muscle metabolism. J Appl Physiol 84: 16671673, 1998.

125.Starkstein SE, Preziosi TJ, Berthier ML, Bolduc PL, Mayberg HS, and Robinson RG. Depression and cognitive impairment in parkinsons-disease. Brain 112: 1141-1153, 1989.

126.Stockler S, Schutz P, and Salomons G. Cerebral creatine deficiency syndromes: Clinical aspects, treatment and pathophysiology. In: Creatine and creatine kinase in health and disease, edited by Salomons $\mathrm{G}$ and Wyss M: Springer Netherlands, 2008, p. 149-166.

127.Tan L. Mood disorders in parkinson's disease. Parkinsonism Relat Disord 18: S74-S76, 2012.

128. Taner B, Aysim O, and Abdulkadir U. The effects of the recommended dose of creatine monohydrate on kidney function. NDT Plus 4: 23-24, 2010.

129. Thanvi BR, Munshi SK, Vijaykumar N, and Lo TCN. Neuropsychiatric non-motor aspects of parkinson's disease. Postgraduate Medical Journal 79: 561-565, 2003.

130.Thomas B and Beal MF. Mitochondrial therapies for parkinson's disease. Mov Disord 25: S155-S160, 2010.

131.Thorsteinsdottir B, Grande JP, and Gatovic VD. Acute renal failure in a young weight lifter taking multiple supplements, including creatine monohydrate. Journal of renal nutrition 16: 341-345, 2006.

132. Tilley BC, Investigators N-P, and The N. A randomized, doubleblind, futility clinical trial of creatine and minocycline in early parkinson disease. Mov Disord 21: S613-S613, 2006.

133. Valastro B, Dekundy A, Danysz W, and Quack G. Oral creatine supplementation attenuates 1-dopa-induced dyskinesia in 6hydroxydopamine-lesioned rats. Behavioural Brain Research 197: 90-96, 2009.

134.van Leemputte M, Vandenberghe K, and Hespel P. Shortening of muscle relaxation time after creatine loading. $J$ Appl Physiol 86: 840-844, 1999.

135.van Nimwegen $M$, Speelman A, Hofman-van Rossum E, Overeem S, Deeg D, Borm G, van der Horst M, Bloem B, and Munneke M. Physical inactivity in parkinson's disease. J Neurol: $1-8$.

136. Vandenberghe $\mathrm{K}$, Goris $\mathrm{M}$, VanHecke P, VanLeemputte $\mathrm{M}$, Vangerven L, and Hespel P. Long-term creatine intake is beneficial to muscle performance during resistance training. $J$ Appl Physiol 83: 2055-2063, 1997.

137. Verbessem P, Lemiere J, Eijnde BO, Swinnen S, Vanhees L, Van Leemputte M, Hespel P, and Dom R. Creatine supplementation in huntington's disease: A placebo-controlled pilot trial. Neurology 61: 925-930, 2003.

138.Vuckovic MG, Li Q, Fisher B, Nacca A, Leahy RM, Walsh JP, Mukherjee J, Williams C, Jakowec MW, and Petzinger GM. Exercise elevates dopamine $\mathrm{d} 2$ receptor in a mouse model of parkinson's disease: In vivo imaging with (18)f fallypride. Mov Disord 25: 2777-2784, 2010.

139. Wallimann T, Wyss M, Brdiczka D, Nicolay K, and Eppenberger HM. Intracellular compartmentation, structure and function of creatine-kinase isoenzymes in tissues with high and fluctuating energy demands - the phosphocreatine circuit for cellular-energy homeostasis. Biochem J 281: 21-40, 1992.

140.Walsh K and Bennett G. Parkinson's disease and anxiety. Postgraduate medical journal 77: 89-93, 2001.

141.Winkler-Stuck K, Kirches E, Mawrin C, Dietzmann K, Lins H, Wallesch CW, Kunz WS, and Wiedemann FR. Re-evaluation of the dysfunction of mitochondrial respiratory chain in skeletal muscle of patients with parkinsons disease. Journal of Neural Transmission 112: 499-518, 2005.

142. Wyss $M$ and Schulze A. Health implications of creatine: Can oral creatine supplementation protect against neurological and atherosclerotic disease? Neuroscience 112: 243-260, 2002. 
143.Xu J, Kao SY, Lee FJS, Song WH, Jin LW, and Yankner BA. Dopamine-dependent neurotoxicity of alpha-synuclein: A mechanism for selective neurodegeneration in parkinson disease. Nature Medicine 8: 600-606, 2002.

144. Yang L, Calingasan NY, Wille EJ, Cormier K, Smith K, Ferrante RJ, and Flint Beal M. Combination therapy with coenzyme q10 and creatine produces additive neuroprotective effects in models of parkinson's and huntington's diseases. Journal of Neurochemistry 109: 1427-1439, 2009.

145.Zhu JH and Chu CT. Mitochondrial dysfunction in parkinson's disease. J Alzheimers Dis 20: S325-S334, 2010. 